
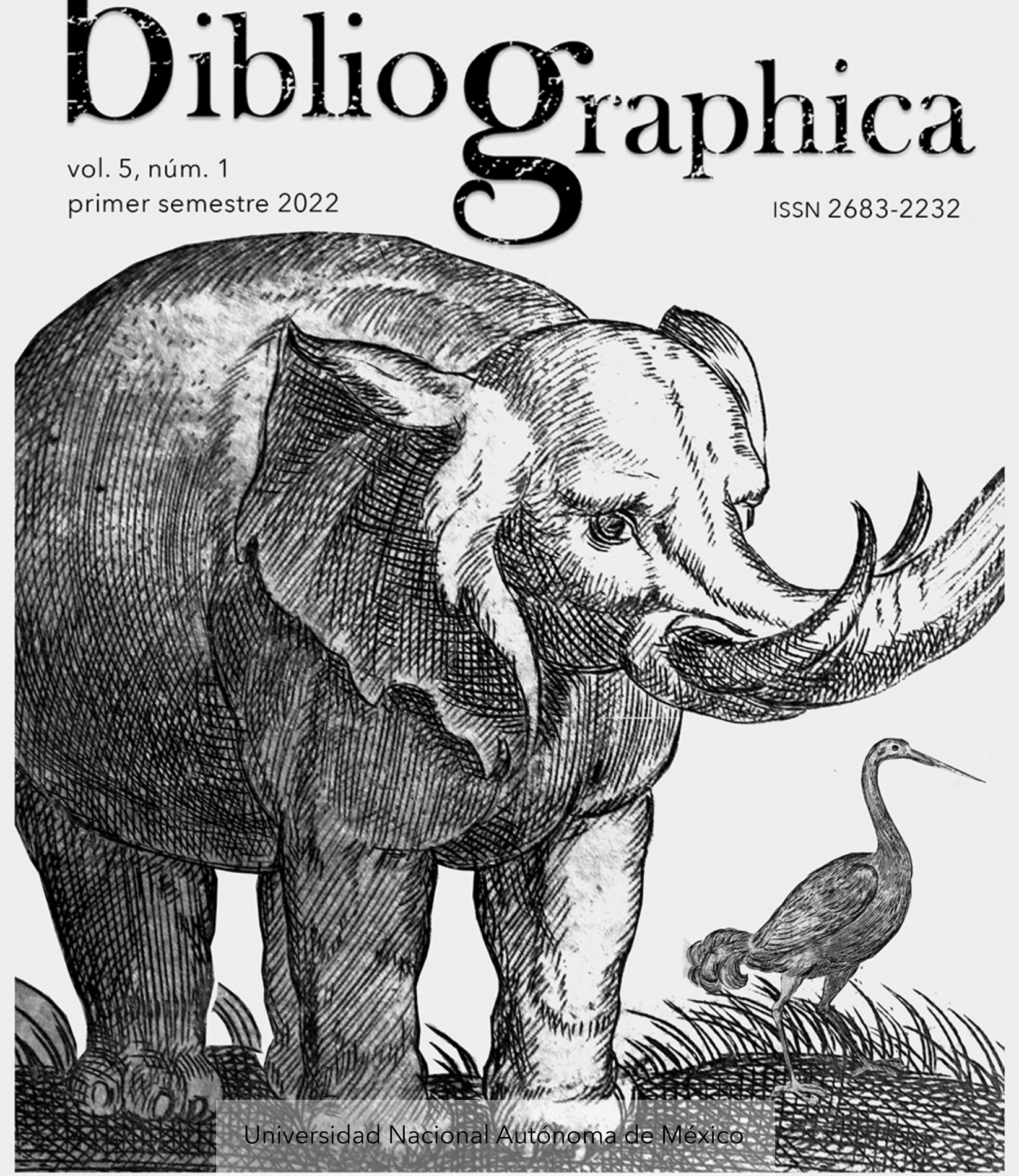


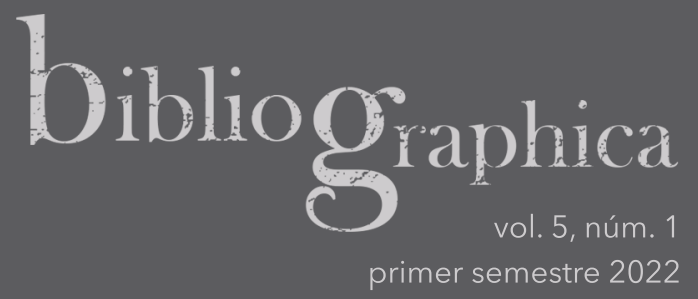

\title{
Descubrimiento de nuevas ediciones mexicanas del siglo XVII: Actas capitulares de la Orden de Predicadores
}

\author{
Discovery of New Mexican Editions of \\ the 17th Century: Capitulary Acts \\ of the Order of Preachers
}

\section{Guadalupe Rodríguez Domínguez}

Universidad Autónoma de San Luis Potosí,

Facultad de Ciencias Sociales y Humanidades,

San Luis Potosí. México

guadalupe.dominguez@uaslp.mx

https://orcid.org/0000-0002-9862-5417

Recepción: 03.11.2021 / Aceptación: 19.12.2021

DOI: https://doi.org/10.22201/iib.2594178xe.2022.1.283 
Resumen

Palabras clave

Abstract

Keywords
Este artículo analiza la impresión de actas capitulares de la Orden de Predicadores en México durante el siglo XVII. En primer lugar, se recurre a la revisión de las actas documentadas por la tradición bibliográfica para cotejar la información con las ediciones localizadas. El procedimiento arroja resultados en tres vías: a) Las coincidencias de los ejemplares localizados y los datos bibliográficos recopilados, b) La identificación de ediciones sine notis que requieren ser asignadas a impresor y lugar, y c) El descubrimiento de nuevas ediciones mexicanas del periodo. Para la identificación de impresor y año de publicación de las ediciones sin datos editoriales se aplican los criterios teórico-metodológicos de la tipobibliografía y la biblioiconografía. Todo ello nos conduce al enriquecimiento del patrimonio documental mexicano con la identificación de seis nuevas ediciones.

Descubrimiento de ediciones; tipobibliografía; biblioiconografía; imprenta mexicana; Orden de Predicadores.

This article analyzes the printing of capitulary acts of the Order of Preachers in Mexico during the 17th century. First, a review of the acts documented in the bibliographic tradition is used to compare the information with the located editions. This procedure provides results in three ways: a) The coincidence of the copies located and the bibliographic data collected, b) The identification of sine notis editions that need to be assigned to a printer and place, and c) The discovery of new Mexican editions of the period. In order to identify the printer and year of publication of editions without editorial data, the theoretical and methodological criteria of typobibliography and biblioiconography are applied. Conclusively, this research leads to the enrichment of the Mexican documentary heritage by identifying six new editions.

Editions discovery; typobibliography; biblioiconography; Mexican press; Order of Preachers. 


\section{Introducción}

El estudio de la imprenta en México en el siglo XVII aún requiere mucha atención, tanto desde la perspectiva general, ${ }^{1}$ es decir, la producción completa conserva$\mathrm{da}^{2}{ }^{2}$ como de la particular, mediante la cual se puedan rescatar los procesos y fenómenos editoriales producidos por hechos o necesidades específicas del virreinato de Nueva España. En esta última línea se desarrolla el presente artículo, que busca aclarar algunos aspectos de la publicación de las actas capitulares de la Orden de Predicadores en el siglo mencionado.

De acuerdo con expertos en la vida interior de la Orden de Predicadores, ${ }^{3}$ las actas capitulares relacionadas con las actividades de esta orden en Nueva España durante el siglo XVI se conservan principalmente en formato manuscrito, ${ }^{4}$

\footnotetext{
${ }^{1}$ Las magnas bibliografías de Juan José Eguiara y Eguren, Bibliotheca mexicana, coord. de Ernesto de la Torre Villar (México: UNAM, 1986); José Mariano Beristáin de Souza, Biblioteca Hispanoamericana Septentrional, 3 vols. (México: UNAM, 1980-1981) y José Toribio Medina, La imprenta en México (1539-1821), 2 vols. (Santiago de Chile: Imprenta del autor, 1907-1908) aportan información valiosa y sin duda siguen siendo pilares de la bibliografía mexicana. No obstante, las necesidades de la labor científica actual requieren de la elaboración de nuevos instrumentos que ofrezcan información más detallada y precisa proveniente del examen minucioso, particularizado, riguroso y exhaustivo de las ediciones del periodo, como la información que ofrecen los repertorios tipobibliográficos.

2 Desde octubre de 2019, desarrollo el proyecto de investigación "Tipobibliografía Mexicana del siglo XVII (1601-1650)" en la Facultad de Ciencias Sociales y Humanidades de la Universidad Autónoma de San Luis Potosí, financiado por el Conacyt bajo la modalidad de Ciencia Básica, convenio A1-S-13259. Uno de sus objetivos principales es la revisión exhaustiva de la producción editorial de la Ciudad de México durante el periodo, así como la elaboración de un repertorio tipobibliográfico con las ediciones de existencia comprobada, de un catálogo de posibles ediciones mexicanas y de otro que consigne las ediciones imaginarias.

${ }^{3}$ Agradezco la información acerca del tema proporcionada por fray Antonio Novoa, del Instituto Dominicano de Investigaciones Históricas de Querétaro, que sirvió como punto de partida de este trabajo.

${ }^{4}$ Me refiero a la conservación en formato manuscrito de actas capitulares que concentran la información de los capítulos provinciales realizados en México. Las actas de los capítulos generales realizados en Europa sí se hallan impresas y circularon en Nueva España; una cantidad nada despreciable se conserva en diversos acervos nacionales. Sólo por poner un ejemplo, la Biblioteca Lafragua (BUAP) resguarda algunos ejemplares -cuyo antiguo poseedor fue el Convento de Santo Domingo de Puebla- de los Capítulos Generales de Roma, 1580 (impresas en Sevilla y/o Roma, s. a.); Venecia, 1592 (en Mantua, s. a.); Avignon, 1561 (Avignon, 1561); Bolonia, 1564 (Salamanca, 1565); Barcelona, 1575 (Bolonia, 1575); Roma, 1583 (Roma, 1583); Roma, 1589 (Madrid, 1590); Sevilla, 1595 (Sevilla, 1595) y Nápoles, 1600 (impresas en Roma, 1600).
} 
aunque sí existen testimonios aislados de actas de capítulos generales impresas en México, como sería el caso de Haec svnt Acta Capitula Generalis Bononiae, por Pedro Ocharte, 1567.5

Por otro lado, las actas tanto de capítulos generales como provinciales (de México) de los siglos XVII y XVIII - de las cuales se conserva una buena cantidadse difundieron principalmente en formato impreso en los diferentes conventos y casas de las provincias novohispanas. Para este trabajo me centraré en algunos testimonios impresos en la época, aunque no presentaré una nómina exhaustiva, debido a que la investigación tipobibliográfica en la que se inscribe este trabajo se encuentra aún en realización. No obstante, las muestras presentadas abarcan casi todo el siglo XVII, por lo que sí dan cuenta del fenómeno editorial que interesa rescatar, reconstruir y dar a conocer.

En este sentido, para identificar y describir el fenómeno de publicación de las actas capitulares dominicas novohispanas a través del análisis material y estructural (temáticamente hablando) de los testimonios, es preponderante realizar las asignaciones de imprenta responsable y posible año de publicación a las ediciones sine notis recolectadas hasta ahora. Como sabemos, existía una gran cantidad de ediciones sin datos editoriales circulando en Nueva España durante el siglo XVII que, por la propia condición de escasez de información, no ha sido documentada en el periodo y lugar que le correspondería, por lo que su asignación es fundamental para reconstruir paulatinamente el complejo panorama editorial del momento y, con ello, tener una idea más clara del mundo de la imprenta novohispana para construir con datos fiables la historia del libro, de la literatura, de las religiones y de la cultura escrita. Siendo así, las posibilidades de identificación editorial que ofrece la aplicación del análisis tipobibliográfico y biblioiconográfico se convierten en punto de partida, ya que los resultados nos permiten ir completando el fragmentado mosaico editorial, y también se convierten en punto de llegada, pues gracias al conocimiento de los talleres de impresión responsables de dichas ediciones, y de las propias características de los impresos, logramos comprender mejor cómo funcionaba el aparato administrativo, legal y religioso del libro impreso novohispano.

Como su nombre indica, las actas capitulares contienen información resultante de los capítulos de la orden. Ya fueran generales o provinciales, la información debía darse a conocer a los frailes dominicos y por ello era importante su

\footnotetext{
${ }^{5}$ Véase Guadalupe Rodríguez Domínguez, La imprenta en México en el siglo XVI (Mérida:
} Editora Regional de Extremadura, 2018), 249-250. 
impresión. Cuando se trataba de capítulos generales, se imprimía un acta por provincia; en el caso de los capítulos provinciales, la propia provincia se encargaba de imprimirlas para sus integrantes. En la época virreinal dichas actas se leían durante las comidas, junto con las reglas y alguna lectura espiritual. ${ }^{6}$

La estructura de las actas impresas revisadas -con algunas variantes, dependiendo de si se trata de capítulos generales o provinciales- está conformada por algunos de los siguientes apartados textuales, ordenados aquí alfabéticamente para una mejor visualización: absolutiones, acceptationes, admonitiones, assignationes, concessiones, confirmationes, declarationes, denuntiationes, denuntationes additio, expositiones, expositiones additio, institutiones, misiones, ordinationes, praecepta, suffragia, suffragia pro vivis, suffragia pro defunctis.

\section{Actas capitulares publicadas en México en el siglo XVII}

Antes de adentrarnos en el análisis tipobibliográfico e iconográfico para asignar las ediciones sin datos editoriales, presento la nómina de 17 de actas impresas en México entre 1600 y 1675, con las respectivas signaturas topográficas del acervo que las resguarda:

1. In nomine domini... [Sin indicaciones tipográficas]

$4^{\circ}$.- $A-B^{4} C^{2}$.- [1] 2-9 ¿10? f.

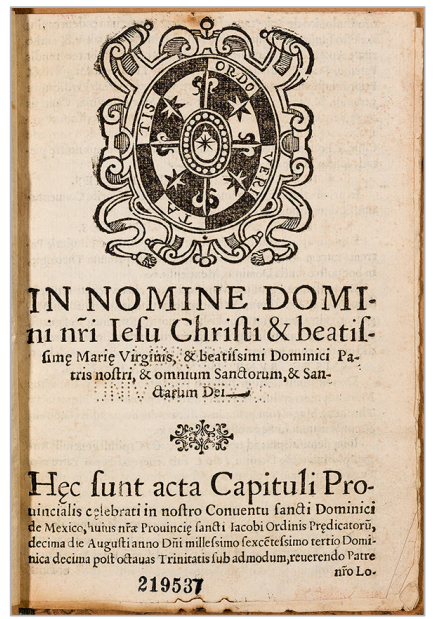

Imagen 1. Benson Latin American Collection, LAC-Z Rare Books GZ 271.2 D713 1603.

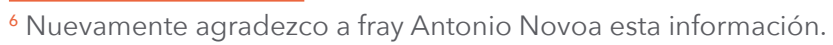


2. Acta Capitvli Provincialis celebrati in Conventv nostro Sancti Dominici de México. [Sin indicaciones tipográficas]

$4^{\circ}$.- A-E ${ }^{4}$ (E4r-v presumiblemente en blanco).- 1 h., 18 f., 1 h. (presumiblemente en blanco).

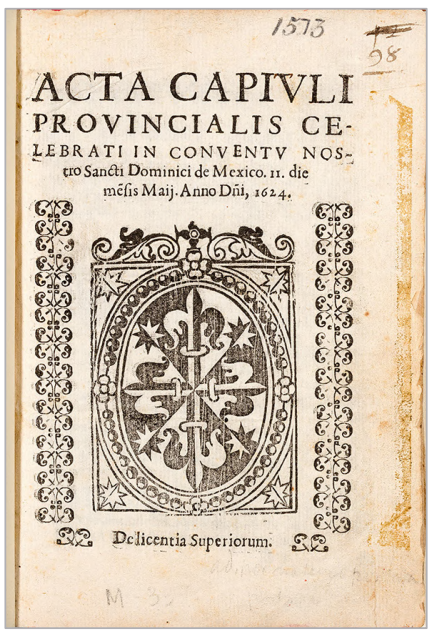

Imagen 2. Benson Latin American Collection, LAC-Z Rare Books BX 3550 P58 D6234 1624.

3. Haec svnt Acta Capituli Provincialis... Mexici: Apud Henricum Martinez, 1604. $[\mathrm{A}]-\mathrm{B}^{4} \mathrm{C}^{2}$.- [1] 2-10 f.

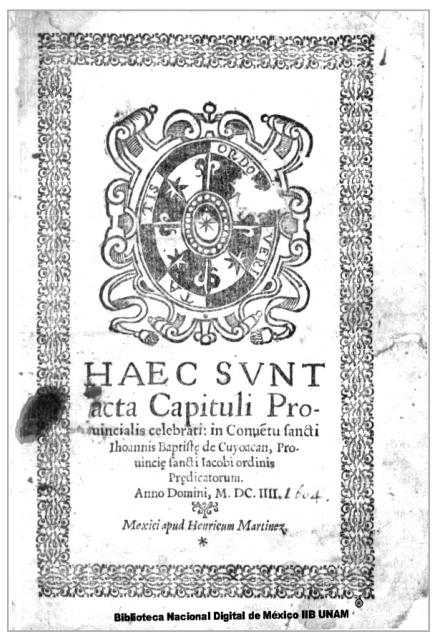

Imagen 3. Biblioteca Nacional de México. RSM 1604 M4 DOM. 
4. In nomine domini nostri lesv Xpi et beatissimae virginis Mariae...

Mexici: Apud Henricum Martinez. [Sin información de año, pero c. 1606] $4^{\circ}$.- A-C (C4 r-v presumiblemente en blanco).- 1 h., 1-20 pp., 1 h. (presumiblemente en blanco).

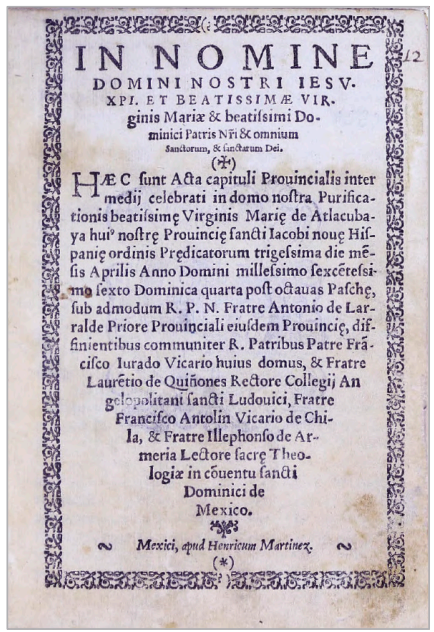

Imagen 4. Biblioteca Nacional de México, RSM 1606 M4DOM.

5. In nomine domini nostri lesv Christi et beatissimi dominici patris nostri... México: Apud Henricum Martinez, Anno 1608.

$4^{\circ}$.- A-C ${ }^{4}$ (C4 r-v en blanco).- 1 h., 2-21 pp., 1 h. (en blanco).

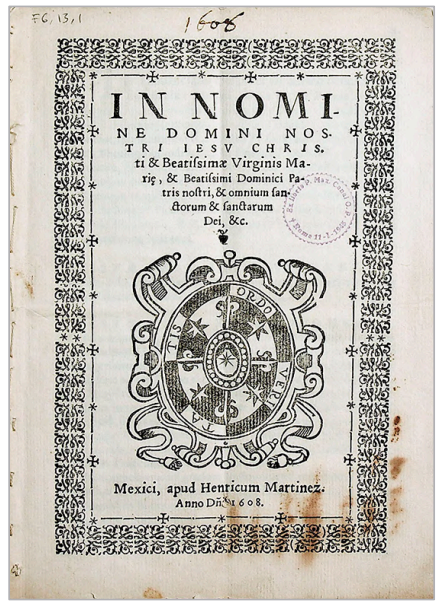

Imagen 5. Archivo de la Orden de Predicadores en Mvéxico, Querétaro, Fondo Provincia de Santiago de México, Sección Gobierno, Serie Capítulos, $1608, F G, 13,1$. 
6. Acta Capitvli Provincialis... Mexici: Ex Officina Henrici Martinez, 1610.

$4^{\circ} .-+^{4} A-B^{4} C^{2}$ (C2 r-v presumiblemente en blanco).- 1 h., 2-23 pp., 2 h. (la última de las cuales presumiblemente en blanco).

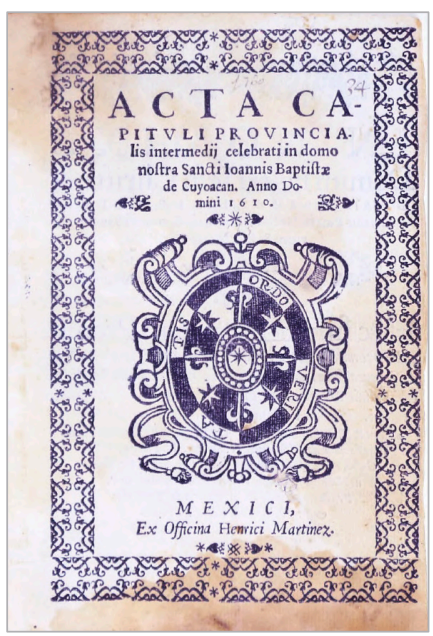

Imagen 6. Biblioteca Nacional de México, RSM 1610 M4 DOM.

7. Acta Capitvli Generalis Parissis. Mexici: Ex Officina Ihoannis Ruyz, 1613.

$4^{\circ}$.- A- $\mathrm{H}^{4} \mathrm{I}^{2}$ (I2 r-v presumiblemente en blanco).- 2 h., [1] 2-31 (=32) pp., 1 h., [1-3] 4-27 (=28) pp., 1 h. (presumiblemente en blanco).

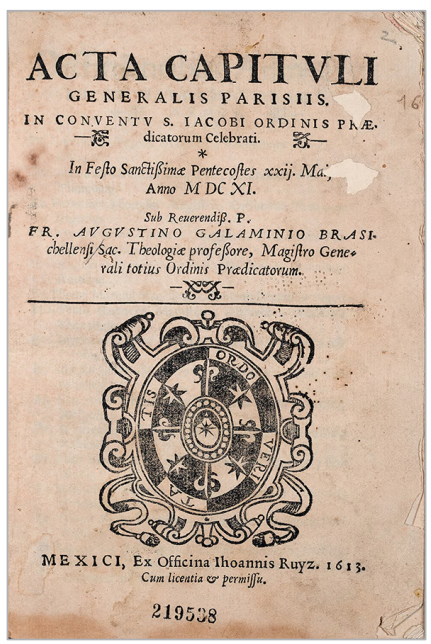

Imagen 7. Benson Latin American Collection, LAC-Z Rare Books G271.2 D713 1613. 
8. Acta Capitvli Generalis Bononię. Mexici: Apud Bachalaurum lioānem de Alcaçar, 1617.

$4^{\circ}$.- A-E $F^{2}$ (F2 r-v presumiblemente en blanco).- 22 h. (la última de las cuales presumiblemente en blanco).

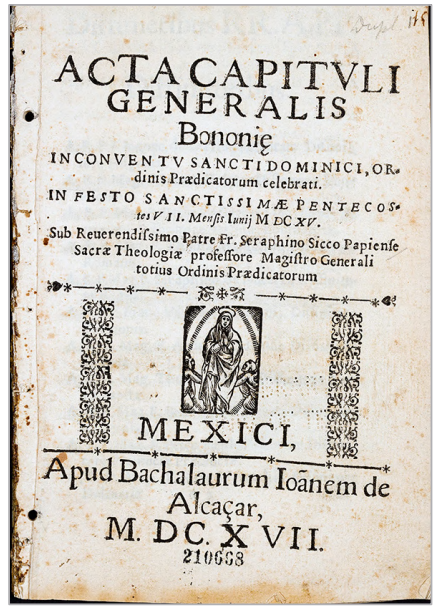

Imagen 8. Benson Latin American Collection, LAC-Z BX 3504 A2 1617.

9. Acta Capitvli Generalis Vlyssiponae... Mexici: Apud lioannem de Alcaçar, Anno 1619.

$4^{\circ}$.- $[A]-D^{4} E^{i 4}$. - 1-18 (=19) ¿[20]? pp.

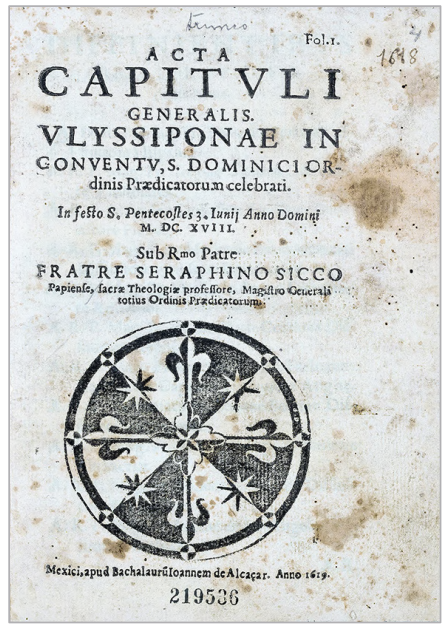

Imagen 9. Benson Latin American Collection, LAC-Z Rare Books GZ 271.2 D716 1619. 
10. Acta Capitvli Generalis Tolosae. Mexici: Bernardo Calderon, Anno 1631. $4^{\circ}$.- A-B ${ }^{4} C^{6}$.- [1] 2-14 f.

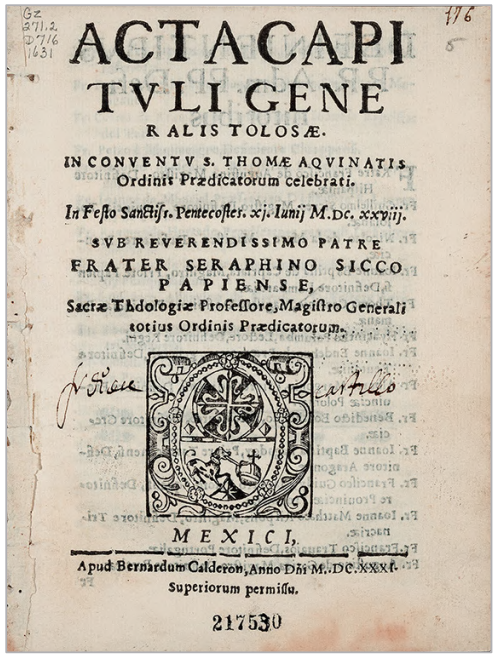

Imagen 10. Benson Latin American Collection, GZ 271.2 D716 1631.

11. Acta Capitvli Provincialis... México: Ex officina Didaci Gutierrez, 1632. $4^{\circ}$.- A-E ${ }^{4}$. [1] 2-20 f.

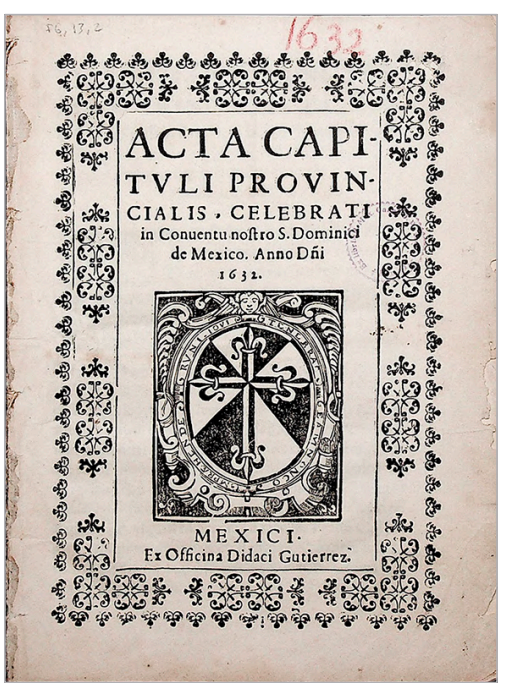

Imagen 11. Archivo de la Orden de Predicadores en México, Querétaro, Fondo Provincia de Santiago de México, Sección Gobierno, Serie Capítulos, 1632, FG, 13, 2. 
12. In nomine domini nostri lesuchisti [sic]... Anno 1633.

[Colofón: En México. En la Imprenta de Francisco Salbago].

$4^{\circ}$.- A-C ${ }^{4}$.- [1] 2-11 f., 1 h.

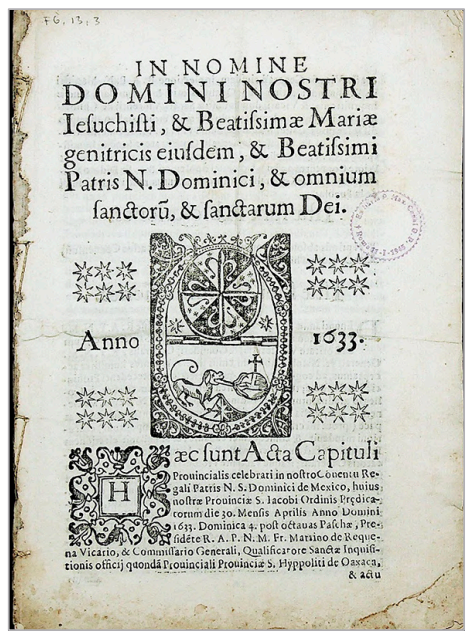

Imagen 12. Archivo de la Orden de Predicadores en México, Querétaro, Fondo Provincia de Santiago de México, Sección Gobierno, Serie Capítulos, 1633, FG, 13, 3.

13. Acta Capituli Provincialis. Mexici: Ex officina loannis Ruyz.

[Sin información sobre año, pero 1646].

$4^{\circ}$.- A-D ${ }^{4}$.- [1-2] 3-16 f.

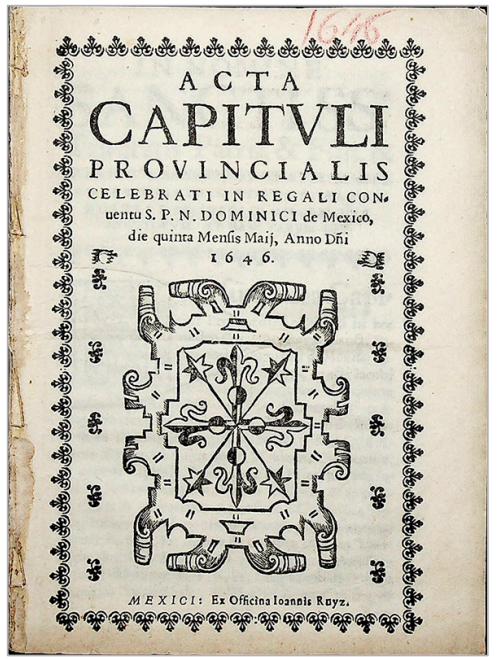

Imagen 13. Archivo de la Orden de Predicadores en México, Querétaro, Fondo Provincia de Santiago de México, Sección Gobierno, Serie Capítulos, 1646, FG, 13, 4. 
14. Acta Capituli Provincialis. Mexici: Ex Tecca et Graphiario Viudę Bernardi Calderon, 1653.

$4^{\circ} .-[]^{2}[A]^{4}$ B6 C-E ${ }^{4}-1$ h., $[1] 2-23 \mathrm{f}$.

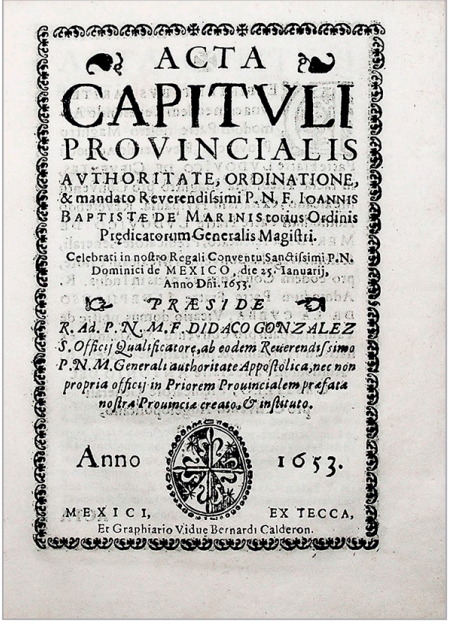

Imagen 14. Archivo de la Orden de Predicadores en México, Querétaro, Fondo Provincia de Santiago de México, Sección Gobierno, Serie Capítulos, 1653, FG, 13, 5.

15. Acta Capituli Provincialis. Mexici: Ex Tecca \& Graphiario Viduę Bernardi Calderon, [1659]. $4^{\circ}$.- [ ] $]^{1}[A]-B^{4} C^{2} .-1$ h., 1-10 f.

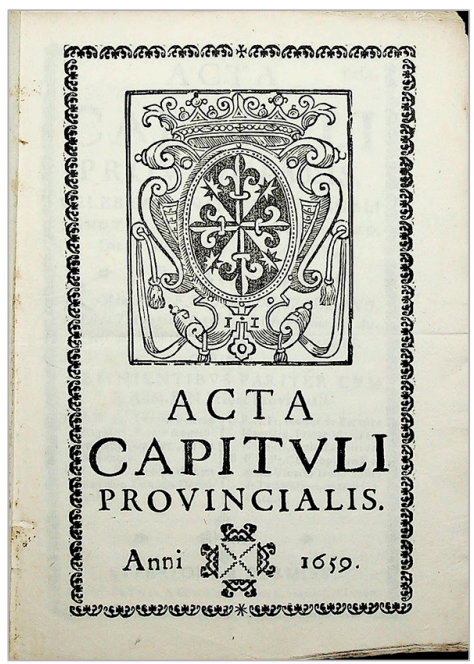

Imagen 15. Archivo de la Orden de Predicadores en México, Querétaro, Fondo Provincia de Santiago de México, Sección Gobierno, Serie Capítulos, 1659, FG, 13, 6. 
16. Acta Capituli Provincialis. Mexici: Apud Ioannem Ruyz, Anno 1663. $4^{\circ}$.- A-E ${ }^{4}$. 1 h., 1-19 f.

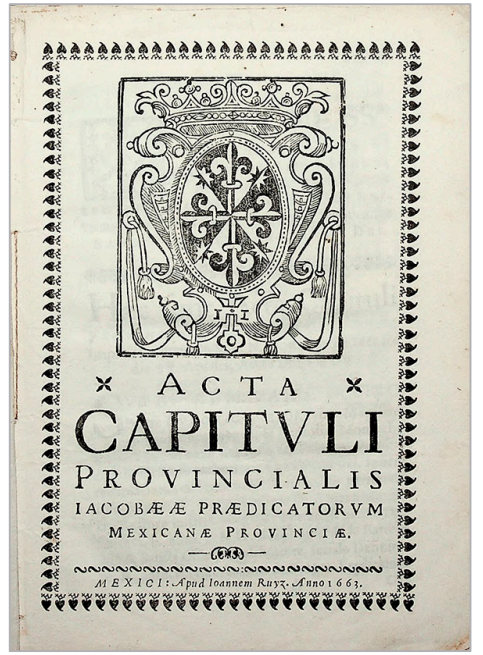

Imagen 16. Archivo de la Orden de Predicadores en México, Querétaro, Fondo Provincia de Santiago de México, Sección Gobierno, Serie Capítulos, 1659, FG, 13, 7.

17. Acta Capituli Provincialis. Mexici: Apud Viudam Bernardi Calderon, 1675. $4^{\circ}$.- [A]-D ${ }^{4} E^{2}$ - 1 h., 1-17 f.

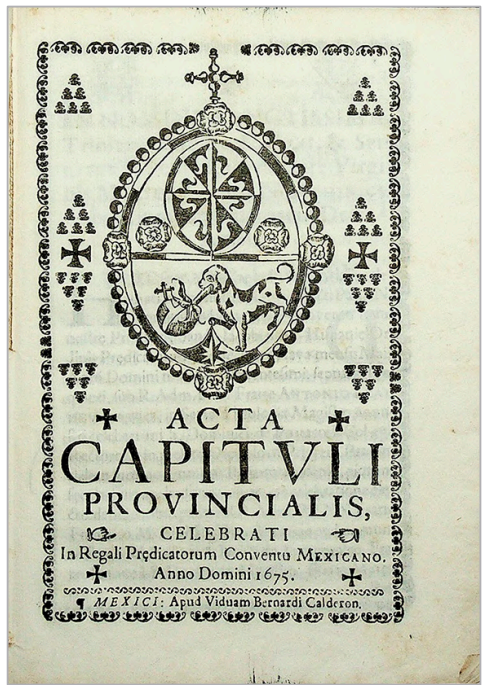

Imagen 17. Archivo de la Orden de Predicadores en México, Querétaro, Fondo Provincia de Santiago de México, Sección Gobierno, Serie Capítulos, 1675, FG, 13, 8. 
La tradición bibliográfica sólo ha documentado algunos de estos testimonios aunque, como se verá, registra otros que aún no he logrado consultar, pero que en cuanto sea posible tener acceso a ellos, se incluirán en el repertorio de impresos mexicanos del siglo XVII de existencia comprobada, actualmente en elaboración.

Vicente de P. Andrade documenta 8 ediciones de actas capitulares impresas en México durante el periodo que nos ocupa: 1613, Juan Ruiz (n. 51-52); 1617, Juan Alcázar (n. 69); 1619, Juan de Alcázar (n. 74); c. 1622, Juan de Alcázar (117); 1624, 11 de mayo, sin impresor (n. 128); 1631, Bernardo Calderón (n. 149); 1646, Juan Ruiz (n. 308); 1697, Francisco Rodríguez Lupercio (n. 1072). ${ }^{7}$

Por otro lado, en 1869 Puttick \& Simpson anuncian en su catálogo de venta de libros un ejemplar de la edición de 1613, Juan Ruiz (n. 12). ${ }^{8}$ José Toribio Medina, en el tomo 2 de La imprenta en México (1539-1821), registra 18 actas capitulares dominicas de la etapa, a cargo de varias imprentas: 1613, 12 de mayo, Juan Ruiz (n. 271); 1616, 13 de mayo, sin impresor (n. 298); 1617, Juan de Alcázar (n. 303); 1619, Juan de Alcázar (n. 310); 1620, Juan de Alcázar (n. 317); 1623, Juan Blanco de Alcázar (n. 347); 1624, 11 de mayo, sin impresor (n. 359); 1631, Bernardo Calderón (n. 412); 1633, Francisco Salvago (n. 434); 1637, Juan Ruiz (n. 480); 1646, Juan Ruiz (n. 617); 1653, Paula de Benavides, viuda de Bernardo Calderón (n. 771); 1659, Paula de Benavides, viuda de Bernardo Calderón (n. 856); 1662, Paula de Benavides, viuda de Bernardo Calderón (n. 894); 1663, Juan Ruiz (n. 903); 1675, Paula de Benavides, viuda de Bernardo Calderón (n. 1120); 1679, Juan Ruiz (n. 1039) y 1683, Francisco Rodríguez Lupercio (n. 1267).9 En otros catálogos, como los de León Pinelo, ${ }^{10}$ Gallardo, ${ }^{11}$ Ramírez, ${ }^{12}$ Salvá, ${ }^{13}$

\footnotetext{
${ }_{7}$ Vicente de P. Andrade, Ensayo bibliográfico mexicano del siglo XVII (México: Imprenta del Museo Nacional, 1899), 50-678.

${ }^{8}$ Puttick \& Simpson, Catalogue of an Extraordinary Collection of Books and Mss. Almost Wholly Relating to the History and Literature of North and South America (Londres: Puttick \& Simpson, 1869), 2.

${ }^{9}$ Medina, La imprenta en México, 57-553.

10 Antonio de León Pinelo, Epítome de la Bibliotheca Oriental y Occidental, náutica y geográfica. Añadido y enmendado nuevamente... por el Marqués de Torre Nueva, 2 vols. (Madrid: Francisco Martínez Abad, 1737-1738).

${ }^{11}$ Bartolomé José Gallardo, Biblioteca española de libros raros y curiosos, 4 vols. (Madrid: Imprenta y Estereotipia de M. Rivadeneyra, 1863-1889).

12 José Fernando Ramírez, Obras, opúsculos históricos, 3vols. (México: Imp. de V. Agüeros, 1898).

${ }^{13}$ Pedro Salvá y Mallén, Catálogo de la Biblioteca de Salvá (Valencia: Imprenta de Ferrer de Orga, 1963).
} 
no aparece ninguna mención a actas capitulares impresas en México durante el siglo XVII.

En síntesis, la suma de actas capitulares de la Orden de Predicadores impresas en México en el XVII registradas por los bibliógrafos asciende a 20 testimonios. Al colacionar los datos de Andrade y Medina, las coincidencias se dan en 6 ediciones, es decir, entre ellos se hallan en común las actas de 1613, 1617, $1619,1631,1646$ y el de la edición sine notis de 1624 (es la misma que enlisto arriba con el número 2) Acta Capitvli Provincialis... [Sin indicaciones tipográficas]. No obstante, se distingue que la información recolectada por los bibliógrafos no coincide en su totalidad con las ediciones de nuestra lista. Para una mejor visualización, se organiza la información en la siguiente tabla:

\begin{tabular}{|c|c|c|c|c|c|c|c|}
\hline & Año & Impresor & Andrade & Medina & $\begin{array}{c}\text { Puttick } \\
\& \\
\text { Simpson }\end{array}$ & $\begin{array}{l}\text { Localizada/ } \\
\text { Fondo }\end{array}$ & $\begin{array}{c}\text { Núm. de } \\
\text { nuestra } \\
\text { lista }\end{array}$ \\
\hline 1 & $\begin{array}{c}1613 \\
12 \text { mayo }\end{array}$ & Juan Ruiz & $51-52$ & 271 & 12 & Benson & 7 \\
\hline 2 & $\begin{array}{c}1616, \\
13 \text { mayo }\end{array}$ & s. i. & --- & 298 & --- & no & 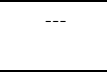 \\
\hline 3 & 1617 & Juan de Alcázar & 69 & 303 & --- & Benson & 8 \\
\hline 4 & 1619 & Juan de Alcázar & 74 & 310 & $-\cdots$ & Benson & 9 \\
\hline 5 & 1620 & Juan de Alcázar & --- & 317 & --- & no & --- \\
\hline 6 & c. 1622 & Juan de Alcázar & 117 & --- & --- & no & --- \\
\hline 7 & 1623 & Juan Blanco de Alcázar & --- & 347 & --- & no & --- \\
\hline 8 & $\begin{array}{c}1624, \\
11 \text { mayo }\end{array}$ & s. i. & 128 & 359 & --- & Benson & 2 \\
\hline 9 & 1631 & Bernardo Calderón & 149 & 412 & $-\cdots$ & Benson & 10 \\
\hline 10 & 1633 & Francisco Salvago & --- & 434 & --- & AOPM & 12 \\
\hline 11 & 1637 & Juan Ruiz & --- & 480 & --- & no & --- \\
\hline 12 & 1646 & Juan Ruiz & 308 & 617 & -- & AOPM & 13 \\
\hline 13 & 1653 & Paula de Benavides & --- & 771 & --- & AOPM & 14 \\
\hline 14 & 1659 & Paula de Benavides & --- & 856 & --- & AOPM & 15 \\
\hline 15 & 1662 & Paula de Benavides & --- & 894 & -- & no & -- \\
\hline 16 & 1663 & Juan Ruiz & --- & 903 & --- & AOPM & 16 \\
\hline 17 & 1675 & Paula de Benavides & -- & 1120 & -- & AOPM & 17 \\
\hline 18 & 1679 & Juan Ruiz & $-\cdots$ & 1039 & $-\cdots$ & no & $-\cdots$ \\
\hline 19 & 1683 & $\begin{array}{l}\text { Francisco Rodríguez } \\
\text { Lupercio }\end{array}$ & --- & 1267 & --- & no & --- \\
\hline 20 & 1697 & $\begin{array}{l}\text { Francisco Rodríguez } \\
\text { Lupercio }\end{array}$ & 1072 & & $-\cdots$ & no & $-\cdots$ \\
\hline
\end{tabular}

Tabla 1. Actas capitulares de la Orden de Predicadores registradas en catálogos bibliográficos. 
De lo que se colige que, respecto a nuestra lista, de los 20 testimonios documentados por la bibliografía especializada aún quedan por localizar 9 ediciones: c. 1622, 1616, 1620, 1623, 1637, 1662, 1679, 1683 y 1697. Pero, a la vez, presento 6 ediciones desconocidas hasta ahora por la crítica.

La ausencia de menciones de estos 6 testimonios en catálogos bibliográficos, de bibliotecas particulares y de venta de libro antiguo los posiciona en la categoría descrita por la Bibliografía Analítica como "descubrimiento de nuevas ediciones", "gracias a la localización de algún ejemplar concreto, no conocido previamente, que resulta ser testimonio único de una nueva edición". ${ }^{14}$ En consecuencia, jestaríamos hablando del descubrimiento de nada menos que de 6 ediciones mexicanas (incluyendo la sine notis presentada al principio de este artículo) impresas a lo largo del siglo XVII!

\begin{tabular}{|c|c|c|c|c|c|}
\hline & Año & Título & Impresor & Fondo & $\begin{array}{l}\text { Núm. de } \\
\text { nuestra lista }\end{array}$ \\
\hline 1 & c. 1603 & In nomine domini & s. i. & Benson & 1 \\
\hline 2 & 1604 & $\begin{array}{l}\text { Haec svnt Acta Capituli } \\
\text { Provincialis... }\end{array}$ & Enrico Martínez & BNM & 3 \\
\hline 3 & c. 1606 & $\begin{array}{l}\text { In nomine domini nostri lesv Xpi } \\
\text { et beatissimae virginis Mariae... }\end{array}$ & Enrico Martínez & BNM & 4 \\
\hline 4 & 1608 & $\begin{array}{l}\text { In nomine domini nostri lesv } \\
\text { Christi et beatissimi dominici } \\
\text { patris nostri... }\end{array}$ & Enrico Martínez & AOPM & 5 \\
\hline 5 & 1610 & Acta Capitvli Provincialis... & Enrico Martínez & BNM & 6 \\
\hline 6 & 1632 & Acta Capitvli Provincialis... & Diego Gutiérrez & AOPM & 11 \\
\hline
\end{tabular}

Tabla 2. Descubrimiento de ediciones mexicanas de actas capitulares de la Orden de Predicadores.

Quedará la duda de filiación de los dos testimonios sine notis, uno de ellos previamente considerado, tanto por Medina como por Andrade, un producto de la imprenta mexicana, sin que ninguno de los dos bibliógrafos expusiera las bases de dicha asignación; y el otro no documentado con anterioridad. Al respecto, más adelante dilucido la identificación de imprenta y el posible año de impresión de estas dos ediciones.

Volviendo a nuestra lista, de las 17 ediciones, sólo las 4 siguientes se refieren a capítulos generales de la Orden de Predicadores (se conserva la misma numeración, para una rápida identificación):

\footnotetext{
${ }^{14}$ Mercedes Fernández Valladares, La imprenta en Burgos (1501-1560) (Madrid: Arco Libros, 2005), 76.
} 
7) Acta Capituli Generalis Parissis. Mexici: Ex Officina Ihoannis Ruyz, 1613.

8) Acta Capitvli Generalis Bononię. Mexici: Apud Bachalaurum lioānem de Alcaçar, 1617.

9) Acta Capitvli Generalis Vlyssiponae... Mexici: Apud lioannem de Alcaçar, Anno 1619.

10) Acta Capitvli Generalis Tolosae. Mexici: Bernardo Calderon, Anno 1631.

Las 13 restantes concentran la información de capítulos provinciales realizados en el Convento de Santo Domingo de México y en el Convento de San Juan Bautista de Coyoacán. Llama la atención que los números 1 y 2 de nuestra lista no cuentan con datos editoriales:

1) In nomine domini... [Sin indicaciones tipográficas].

2) Acta Capitvli Provincialis celebrati in Conventv nostro Sancti Dominici de México. [Sin indicaciones tipográficas].

\section{Asignación de impresores y años de publicación}

Para hacer el análisis tipobiblioiconográfico, que conduce a la identificación del impresor responsable de los testimonios y su posible año de publicación, ofrezco por separado la descripción tipobibliográfica de cada uno de ellos, así como su análisis material y algunas imágenes de los mismos:

In nomine domini. [Sin datos editoriales].

$4^{\circ}$.- A-B ${ }^{4} C^{2}$.- [1] 2-9 ¿10? f.- L. red. y curs.- ¿2.5? pls.

Tipos de 3 fundiciones: c. $200 \mathrm{R}$ (título), $94 \mathrm{R}$ (texto), $94 \mathrm{C}$ (texto).

Erratas en sing.: Aij (Aiij).

[A]1 r: Portadilla:

[Grab. xil. de Orden de Predicadores dentro de medallón oval ornamental] | IN NOMINE DOMI- | ni ni le [u Chri ti \& beati - | |imę Marię Virginis, \& beati |simi Dominici Pa- | tris no |tri, \& omnium Sanctorum, \& San- | ctarum Dei --

[A]1 r-f. 9 v: Texto del acta capitular: [Cuatro adornos tipográficos al centro] | Hęc funt acta Capituli Pro- | uincialis cęlebrati in no |tro Conuentu |ancti Dominici | de Mexico...

f. ¿10 r-v?: Desconocido. 


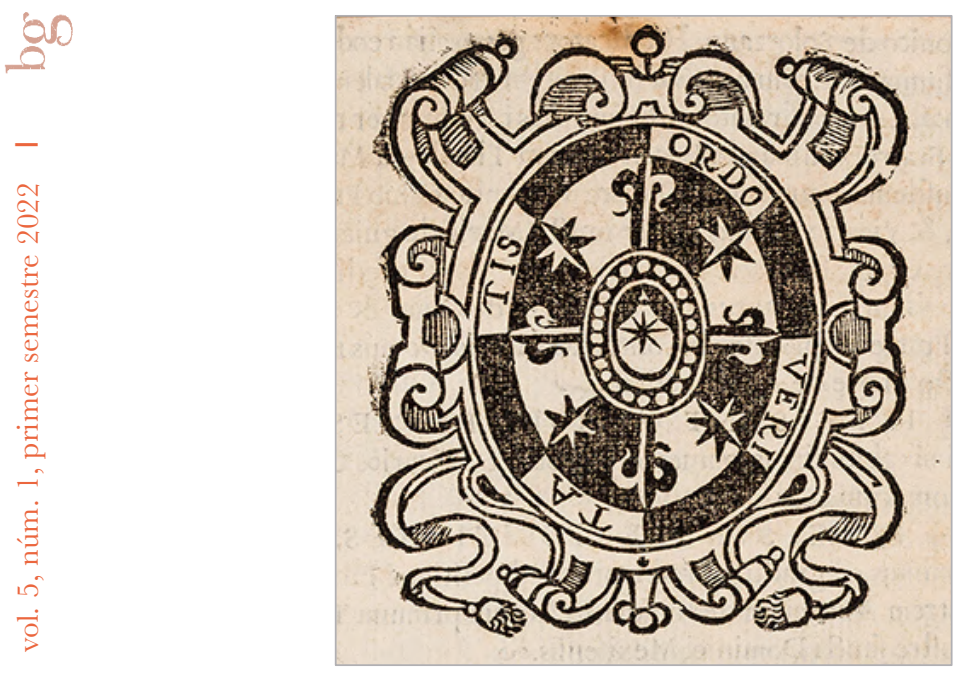

Imagen 18. Miniatura extraída de la Imagen 1.

Se observa un grabado xilográfico de la Orden de Predicadores $(65 \times 73$ $\mathrm{mm}$ ) (Imagen 18) haciendo de portadilla; inmediatamente después se presenta el título (ver Imagen 1) y al final de éste cuatro adornitos tipográficos sirven de separación entre título y texto. Al observar la descripción tipobibliográfica se advierte que se trata de un impreso en formato $4^{\circ}$, formado por 2 cuadernos de 4 hojas cada uno (A-B) y un cuaderno de 2 hojas (C), aunque la segunda hoja de este último se encuentre mutilada en el ejemplar revisado. El texto está compuesto con 3 fundiciones tipográficas: c. $200^{15} R$ (redonda) para las dos primeras líneas del título y la primera línea del texto, y $94 \mathrm{R}$ (redonda) y $94 \mathrm{C}$ (cursiva) ${ }^{16}$ para el resto del texto. La obra se divide en varios apartados textuales, con la particularidad de la ausencia de textos preliminares legales y administrativos, como aprobaciones, licencia, censura, tasa, etc.

Respecto al año de publicación, el catálogo de la Benson Latin American Collection le asigna 1603, ya que se trata del acta del capítulo provincial de ese

\footnotetext{
${ }^{15}$ La codificación de la fundición tipográfica se extrae aplicando el axioma Proctor-Haebler, perfeccionado por Norton, que consiste en medir 20 líneas continuas del mismo texto y expresar el resultado en milímetros. En caso de que no se encuentren las 20 líneas seguidas, la medida se obtiene mediante extrapolación por regla de 3, señalando el resultado con c. (circa), antes del número. Fernández Valladares, La imprenta en Burgos, 121.

${ }^{16}$ En adelante, anotaré solamente $\mathrm{R}$ para referirme a los tipos redondos, y $\mathrm{C}$ para los cursivos.
} 
año. Considero que el año es acertado; el comportamiento de publicación de todas las actas de los capítulos provinciales consultadas indica que se mandaban a imprimir en fechas cercanas a la celebración de cada capítulo, con la intención de que la información pudiera circular y conocerse entre los distintos conventos de la provincia, para su aplicación inmediata.

En lo que se refiere a la identificación del impresor, el grabado xilográfico de mismo diseño, con idéntica medida $(65 \times 73 \mathrm{~mm})$, aparece en la producción de Enrico Martínez durante la primera década del siglo XVII. Martínez lo utiliza en la portada de varias actas capitulares (ver imágenes 3, 5 y 8). El grabado se encuentra documentado, descrito, analizado, reproducido de manera separada y en contexto dentro de la portada del acta capitular impresa en $1608,{ }^{17}$ como parte de los materiales utilizados por la imprenta de Enrico Martínez en el siglo XVII, con nomenclatura rb-martinez-17-011 en el Repositorio Biblioiconografía mexicana de los siglos XVI y XVII. Se comprueba que se trata del mismo taco de madera por el daño, en forma de muesca, en el bucle superior derecho. ${ }^{18}$

Es curioso advertir que este grabado también aparece en los impresos de Juan Ruiz (ver Imagen 6), y sin duda alguna se trata del mismo taco de madera, pues se observa el daño en forma de muesca en idéntico lugar, a propósito de lo cual podría comprobarse lo que Maza señaló en 1991: Juan Ruiz declaró ser hijo de Enrico Martínez, por lo que se supone que la imprenta del segundo pasó a manos del primero.

En este sentido podría pensarse que la edición pudo correr a cargo de Ruiz, pero la temporalidad ofrece la clave de la asignación de imprenta: Enrico Martínez cesa su producción impresa en 1611 y la firma de Juan Ruiz como impresor figura a partir de 1613, aunque en 1612 su nombre como editor se incluye en Reformación de las tablas y quentas de plata y de la que tiene el oro..., de la imprenta de Diego López Dávalos. ${ }^{19}$ Considerando que las actas se imprimían en fecha cercana a la realización de cada capítulo y que la información del testimonio en cuestión es relativa al capítulo de 1603, no queda duda

17 Guadalupe Rodríguez Domínguez, Biblioiconografía mexicana de los siglos XVI y XVII. Repositorio institucional de la Universidad Autónoma de San Luis Potosí (México, 2020), acceso el 4 de febrero de 2022, www.biblioiconografiamexicana.buap.mx.

18 http://www.biblioiconografiamexicana.buap.mx:8180/dig/browse/item.jsp?repository =biblioiconografia\&map=0\&key=biblioiconografia_imprenta_de_enrico_martinez_ 1601_1611_20201108231812_7eb8.xml\&num=10.

${ }^{19}$ Francisco de la Maza, Enrico Martínez: cosmógrafo e impresor de Nueva España (México: UNAM, IIB, 1991), 28. 
de que la edición coincide con el periodo de trabajo activo de la imprenta de Enrico Martínez.

En otro orden de ideas, también existe la posibilidad de que el taco de madera fuera propiedad de la Orden de Predicadores, que lo entregaba a la casa impresora elegida para ser integrado en la edición de las actas capitulares. A propósito de esta situación, Manuel José Pedraza Gracia ha documentado diversas modalidades de posesión de materiales iconográficos por parte de algunas imprentas peninsulares durante los siglos XVI-XVIII; en el tercer caso presentado por el investigador se encuentran los tacos de madera, "[that] remain in the possesion of persons or entities other than the printer, who nevertheless would retain those materials fulfilling the same function that logically corresponded to him, such as printer's marks and monograms".20

De este modo, ateniéndonos exclusivamente a la temporalidad, cualquier otro taller de impresión activo en México durante los primeros años del siglo XVII pudo haber sido el responsable de la edición en cuestión: Melchor Ocharte, Diego López Dávalos o Fernando Balli. Por lo que, para terminar de apuntalar la asignación de imprenta aplicamos el procedimiento de combinación de caracteres formulado por Vervliet ${ }^{21}$ y utilizado de manera precisa por Norton ${ }^{22}$ para el análisis de postincunables españoles, al que sumamos el principio metodológico de justificación de matrices diseñado por Moll: ${ }^{23}$ las fundiciones c. 200 R, 94 R y $94 \mathrm{C}$, utilizadas para la impresión del acta sine notis, coinciden en tamaño, diseño y justificación con las que Enrico Martínez poseía y usaba para la composición de sus impresos durante la primera década del siglo XVII. ${ }^{24} \mathrm{~A}$ manera

\footnotetext{
${ }^{20}$ Manuel José Pedraza Gracia, "Illustrating and Publishing on the Hand-Press in Spain from Fifteenth to the Eighteenth Century: The Ownership of Icono-Typographic Resources", en Illustration and Ornamentation in the Iberian Book World, 1450-1800, ed. de Alexander S. Wilkinson (Leiden: Brill, 2022), 82.

${ }^{21}$ Hendrik D. L. Vervliet, Sixteenth-Century Printing Types of the Low Countries, prefacio de Harry Carter (Ámsterdam: Menno Hertzberger \& Co., 1968).

22 Frederick John Norton, "Typographical Evidence as an Aid to the Identification and Dating of Unsigned Spanish Books of the Sixtheenth Century", Iberoromania, núm. 2 (1970): 96-103.

${ }^{23}$ Jaime Moll, "La justificación de las matrices y el estudio de las letrerías", en De la imprenta al lector. Estudios sobre el libro español de los siglos XVI al XVIII (Madrid: Arco Libros, 1994), 109-118.

${ }^{24}$ Para el análisis tipográfico he aplicado el método de Proctor-Haebler, que permite percibir las características distintivas de las tipografías a partir del cotejo de varios impresos, al que se suma el principio metodológico de la combinación de caracteres formulado por Vervliet (1968) y perfeccionado en su aplicación al análisis de los postincunables penin-
} 
de ejemplo de los rigurosos principios metodológicos aplicados, analicemos la coincidencia de diseño y justificación de matrices de la fundición c. 200 R en la edición sine notis (Imagen 19) y en el folio 2r de la edición de 1604 de Enrico Martínez (Imagen 20):

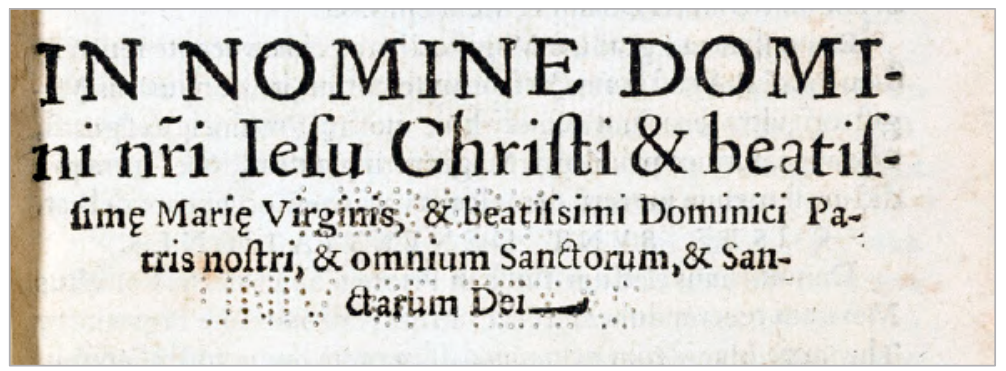

Imagen 19. Recorte de Imagen 1.

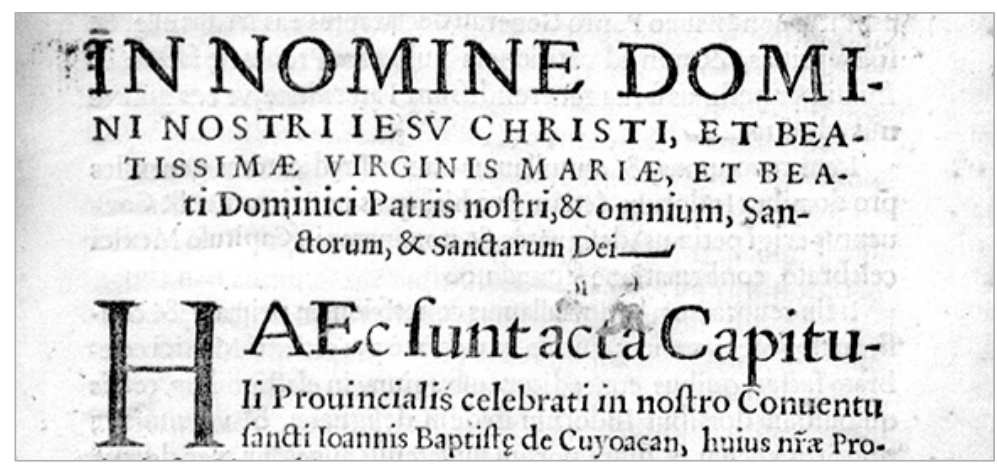

Imagen 20. Haec svnt Acta Capituli Provincialis...

Mexici: Apud Henricum Martinez, 1604, f. 2r.

Biblioteca Nacional de México, RSM 1604 M4 DOM.

sulares por Norton (1970), así como el método de justificación de matrices diseñado por Moll (1994). Esta combinación de principios metodológicos fue establecida por la doctora Mercedes Fernández Valladares para aplicarse en las investigaciones desarrolladas en el Seminario Permanente de Bibliografía Material y Análisis Tipográfico (Sebimat) bajo su dirección, adscrito al Instituto Universitario Menéndez Pidal de la Universidad Complutense de Madrid. 
La primera línea de ambos textos "IN NOMINE DOMI" forma parte de la misma fundición, por lo que el diseño de cada una de las letras de la caja alta es idéntico. Obsérvese la línea de asiento de las letras I, N, M, E y la ligera disminución de la curva de la panza de la $O$ en la parte superior izquierda. Adviértase también el minúsculo ángulo que sale en la mitad del asta de la "s" alta ( $\int$ ) en

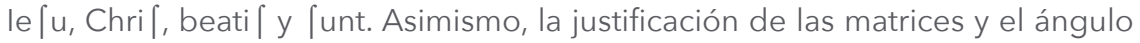
de inclinación de los tipos es el mismo en ambas muestras. Muchas otras similitudes se encuentran al realizar el análisis de las fundiciones $94 \mathrm{R}$ y $94 \mathrm{C}$ y de los adornos tipográficos, pero no se desglosan aquí por cuestiones de espacio.

En conclusión, el riguroso procedimiento de análisis tipobiblioiconográfico realizado permite asignar esta edición, quedando asentada como: In nomine domini. [Sin datos editoriales, pero México: Enrico Martínez, c. 1603].

Pasemos ahora a la otra edición sin información tipográfica (Imagen 2), cuya descripción tipobibliográfica reza:

Acta capitvli provincialis celebrati in Conventv nostro Sancti Dominici de México. [Sin datos editoriales].

4.- $A-E^{4}$ (E4r-v presumiblemente en blanco).- 1 h., 18 f., 1 h. (presumiblemente en blanco). - L. red. y curs.- 5 pls.

Tipos de 6 fundiciones: c. 240 R (portada), c. 180 R (portada), c. 118 R (portada), c. $95 \mathrm{C}$ (texto), $95 \mathrm{R}$ (texto), $84 \mathrm{R}$ (texto).

Inic. grab.- Con recl.- Texto en español y latín, a línea tirada y a dos columnas.

[A]1 r: Portada:

ACTA CAPIVLI | PROVINCIALIS CE- | LEBRATI IN CONVENTV NOS- | tro Sancti Dominici de Mexico. Il. Die | mē [is Maij. Anno Dñi, 1624. | [Dos líneas de adornos tipográficos flanqueando grab. xil. de escudo de la Orden de Predica dores, dentro de un marco de filete doble] | [dos adornos tipográficos] | De licentia Superiorum. [Dos adornos tipográficos]

A1 v: En blanco.

f. $1 \mathrm{r}$-11 r: Texto del acta capitular: [Cenefa formada por una fila de adornos tipográficos] | IN NOMINE SANCTIS- | SIMAE, ATQVE INDIVIDVAE TRI- | nitatis Patris, \& Filij, \& Spiritus |ancti, \& Beati |- | |imæ Deipa æ |emper Virginis MARIAE... f. 11 r-17 v: Lista de asignaciones, a dos columnas: [Cenefa formada por una fila de adornos tipográficos] ISTE SVNT ASSIGNATIONES. | IN CONVENTV S. 
P. N. DOMINICI DE | Mexico, a jsignamus. | R. P. Fr. Ildephon [um de | Almeria Magi |trum.|

f. 17-18 v: Declaraciones: [Cenefa formada por una fila de adornos tipográficos] | ( $\left.D^{2}\right)$ Eclaramos, que los Religio[os, que no e[tuuieren expre $\lceil-1$ |amente a $\lceil$ ignados, pertenecen à aquiellas ca $\lceil a s$, don- I de e $\lceil$ tauan a $\lceil$ signados...

E4 r-v: Presumiblemente en blanco.

Se presenta una portada con el título compuesto en tres fundiciones tipográficas: c. 240 R, c. 180 R, c. 118. Enseguida tenemos un grabado de la Orden de Predicadores dentro de un doble marco oval con cuentas y flores, todo enmarcado a su vez por un rectángulo de doble filete con estrellas en las enjutas y coronado por una cruz al centro y hojas de acanto. El grabado se encuentra flanqueado por dos filas de adornos tipográficos. Por último, a pie del grabado la frase "De licentia Superiorum", flanqueada por adornos tipográficos.

Como se detalla en la descripción tipobibliográfica, en la siguiente hoja inicia directamente el texto del acta capitular, al que sigue la lista de asignaciones, y por último se encuentran las declaraciones.

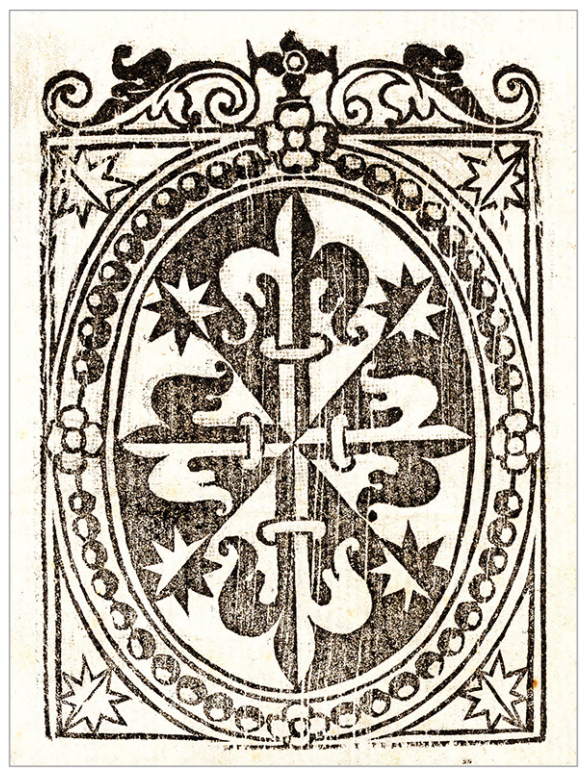

Imagen 21. Miniatura extraída de la Imagen 2. 
El grabado xilográfico $(63 \times 90 \mathrm{~mm})$ de la portada no ha sido documentado aún en ninguno de los repertorios de materiales de las imprentas mexicanas del periodo. No obstante, sí es posible realizar la asignación de la imprenta responsable de dicha edición, ampliando la aplicación del método tipobiblioiconográfico.

A propósito, desde 2010 Fernández Valladares, en su magistral propuesta presentada en Oxford, planteaba que

para abordar de manera consistente esa labor prioritaria de identificación editorial resulta imprescindible disponer de inventarios descriptivos normalizados, repertorios visuales y atlas exhaustivos de los materiales iconográficos (como también, desde luego, de los tipográficos, fundamentales para verificar la fiabilidad de las identificaciones), organizados atendiendo a las distintas imprentas y convenientemente individualizados, codificados, reproducidos, descritos y clasificados a partir de la metodología analítica material subyacente a la elaboración de los modernos repertorios tipobibliográficos, que se fundamenta-como premisa irrenunciable- en el intento de exhaustividad en cuanto al alcance de la recopilación de los corpora delimitados, pues los muestrarios selectivos o parciales de algunos materiales (de los más vistosos, o accesibles, o repetidos, o conocidos, etc.) impiden aplicar análisis comparados que arrojen datos discriminantes, es decir, evidencias bibliográficas para la asignación editorial. ${ }^{25}$

Sin bien el proyecto del que deriva este artículo está en marcha, los muestrarios de tipografías e iniciales grabadas que hemos recopilado se encuentran suficientemente documentados, lo cual permite superar las limitaciones de no haber encontrado aún el grabado de la Imagen 21.

Antes de continuar con el análisis tipobiblioiconográfico, habrá que puntualizar que, como indica la portada, el acta recaba los datos del Concilio Provincial celebrado el 11 de mayo de 1624 en el Convento de Santo Domingo de la Ciudad de México. Por ello, la temporalidad permite acotar el trabajo a alguna

${ }^{25}$ Fernández Valladares, "De la tipobibliografía a la biblioiconografía. Consideraciones metodológicas para un Repertorio digital de materiales iconográficos de los impresos españoles del siglo XVI", en La palabra escrita e impresa: libros, bibliotecas, coleccionistas y lectores en el mundo hispano y novohispano: in memoriam Víctor Infantes \& Giuseppe Mazzocchi, ed. de Juan-Carlos Conde y Clive Griffin, Spanish Series 172 (Nueva York; Oxford: s. e., 2020), 64-65. 


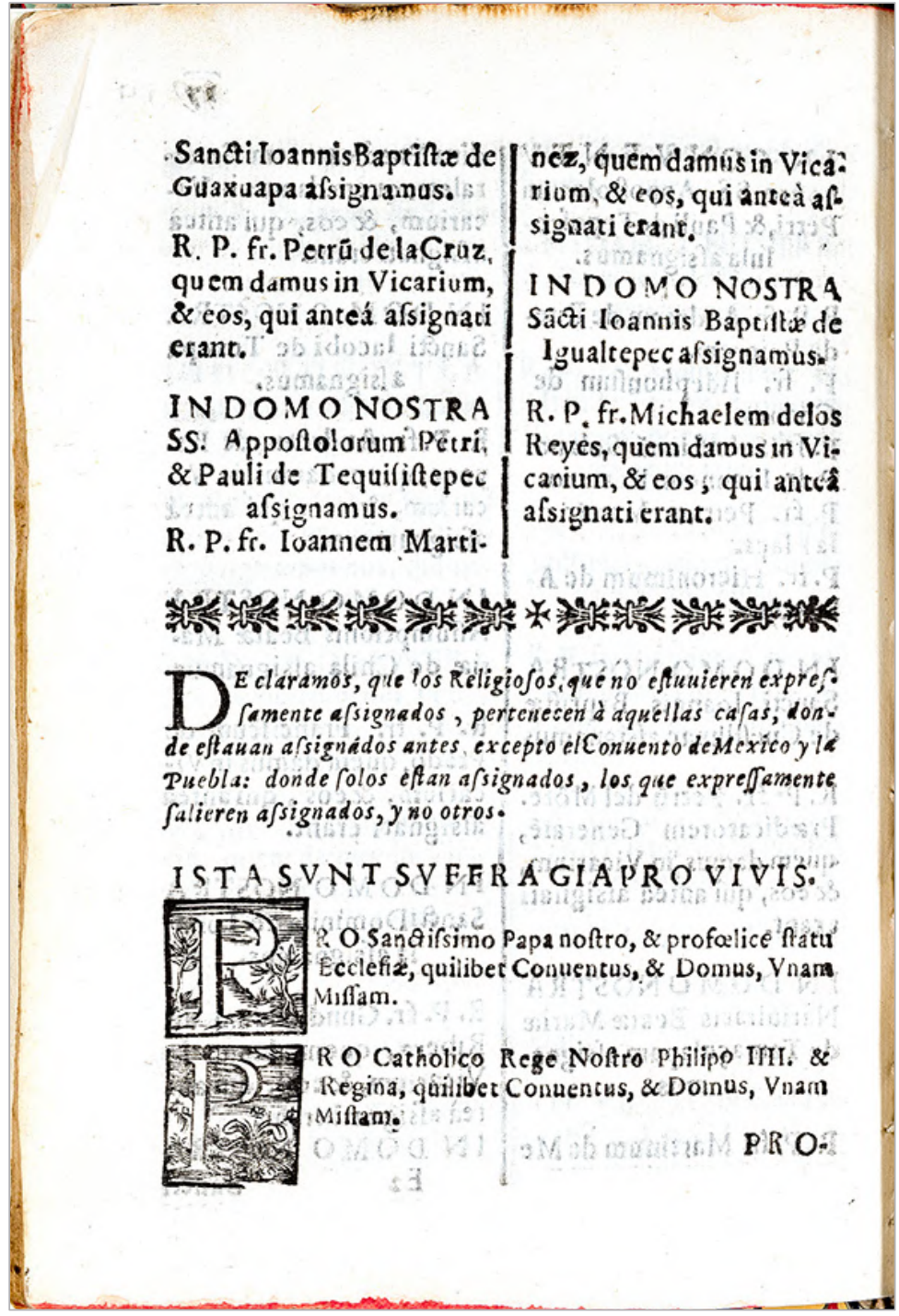

Imagen 22. Benson Latin American Collection, LAC-Z Rare Books BX 3550 P58 D6234 1624. 
Los muestrarios de materiales de las imprentas mexicanas activas en la segunda década del siglo indican que solamente un taller utilizó estas series de iniciales grabadas con paisaje agreste de fondo. Estas iniciales " $\mathrm{P}$ " $\mathrm{y}$ otras letras de las mismas series aparecen en dos ediciones a cargo de Juan de Alcázar: 1620, Historia del glorioso San Guillermo, y 1624, Primera parte de la crónica agustiniana de Michoacán. Asimismo, aplicando el principio metodológico de combinación de caracteres, las fundiciones tipográficas c. 240 R, c. 180 R, c. 118 $\mathrm{R}$, c. 95 C, $95 \mathrm{R}, 84 \mathrm{R}$ aparecen repetidamente en las obras publicadas por dicho impresor durante 1617-1624, y son también las utilizadas para la composición de las actas de 1617 y 1619 presentadas en nuestra lista (núms. 7 y 8). De modo que los datos completos de identificación de esta edición quedan asignados como Acta capitvli provincialis celebrati in Conventv nostro Sancti Dominici de México. [Sin datos editoriales, pero México: Juan de Alcázar, c. 1624].

\section{¿Y los preliminares legales?}

Por cuestiones de espacio no es posible incluir aquí las descripciones tipobibliográficas de las 17 ediciones. No obstante, en términos de contenido habrá que resaltar que todas las ediciones del siglo XVII aquí presentadas carecen de los preliminares administrativo-legales preceptivos de la época: aprobaciones, censuras, licencia, privilegio, tasa, etc. Lo más que se encuentra en algunas de ellas son las menciones en la portada: "Cum licentia \& permissu" (1613), "De licentia superiorum" (1624), "Superiorum permissu" (1631).

Es verdad que la ausencia de preliminares legales en ediciones mexicanas se advierte en los primeros impresos, particularmente los publicados desde la llegada de la imprenta a territorio continental en 1539 y hasta 1555, año en que se efectúa el primer Concilio Mexicano, a partir del cual se regula la impresión de textos. Más adelante, con la publicación de la Pragmática de 1558, se aplica sistemáticamente la legislación sobre la actividad impresora novohispana.

Por la cercanía temporal de estas directrices de control del libro, es comprensible que el único testimonio conocido impreso en México en el siglo XVI (Haec svnt acta capitvla generalis bononiae, Pedro Ocharte, 1567) incluya la licencia de impresión emitida por el segundo arzobispo de México, fray Alfonso de Montúfar, en México a 3 de abril de 1567, "para que cualquier impresor pueda imprimir las actas capitulares" de la Orden de Santo Domingo.

En cambio, llama la atención que ninguna de las ediciones del siglo XVII cuente con los preliminares requeridos por la legislación del libro. Por tanto, 
la publicación de las actas capitulares analizadas entraría en la categoría del singular fenómeno que en 2005 Mercedes Fernández Valladares señaló para el ámbito peninsular, acerca de las ediciones privadas o particulares, y que Fernando Bouza refrendó con el análisis de otros casos en 2014.

Fernández Valladares -en su imprenta burgalesa del siglo XVI- identificó una edición de la Compañía de Jesús que carecía de licencia, tasa y fe de erratas, y a pesar de ello pudo circular sin problemas precisamente por estar destinada al uso interno. ${ }^{26}$ Posteriormente, Bouza señaló que este fenómeno no era perseguible durante el Antiguo Régimen, es decir, estaba permitido imprimir obras sin los preceptivos permisos y, por tanto, sin los preliminares correspondientes, no incurriendo en delito siempre y cuando las tiradas se destinaran a la circulación privada y no a la venta. ${ }^{27}$

Así, todo indica que, al igual que la Metrópoli, Nueva España vivió una relajación en los trámites del control de libro, lo cual explica la circulación de gran cantidad de ediciones novohispanas del siglo XVII que, por no haber pasado por los preceptivos protocolos de la censura o del control administrativo, no incluyen los preceptivos textos legales preliminares.

\section{Conclusiones}

En primer lugar, la impresión de actas capitulares localizadas que abarcan todo el siglo XVII habla de una práctica editorial dominica ininterrumpida, que sirve de apoyo a la difusión de la información reguladora importante para la vida interior de sus conventos. El hecho de que se cambie del formato manuscrito, más practicado en el siglo XVI, al impreso durante el XVII habla de una organización y de una vida pujante, además de activa, al interior de los conventos dominicos novohispanos.

En segundo lugar, al acta documentada por Medina y Andrade correctamente como una edición mexicana de 1624, agrego la identificación del taller de impresión responsable, cuestión fundamental sin la cual no se podría afirmar que se trata de un producto de la imprenta manual mexicana del siglo XVII. Así, mediante la aplicación del análisis tipobiblioiconográfico asigno la edición a la

\footnotetext{
${ }^{26}$ Fernández Valladares, La imprenta en Burgos, 184-186, y nota a pie 179.

27 Información presentada por Fernando Bouza en su conferencia magistral "Reinos, imprentas y mercados en tiempos de Felipe IV. El libro en la monarquía y una monarquía en libros", II Foro Editorial de Estudios Hispánicos y Americanistas, Cádiz, abril de 2011.
} 
imprenta de Juan de Alcázar, por lo que ahora nuestro patrimonio bibliográfico cuenta con una edición más de este taller de impresión.

En tercer lugar identifico, también mediante el análisis tipobiblioiconográfico, el impresor responsable y año aproximado de publicación de la otra edición sine notis: Enrico Martínez, 1603, con lo cual se suma una edición más de esta imprenta a nuestro patrimonio bibliográfico. Además de la identificación del impresor responsable de dicha edición, profundizo en la información que permite comprobar a través de la materialidad, al menos en un caso específico de análisis biblioiconográfico, la suposición de Francisco de la Maza acerca de que la imprenta de Enrico Martínez pasó a manos de Juan Ruiz.

En suma, con este trabajo agrego al panorama editorial mexicano del siglo $\mathrm{XVII}$, a la historia del libro impreso mexicano $\mathrm{y}$, en consecuencia, al patrimonio documental mexicano, 6 ediciones desconocidas por la tradición bibliográfica, que representan el descubrimiento de nuevas ediciones, desde la perspectiva de la tipobibliografía:

1. In nomine domini. [Sin datos editoriales, pero México: Enrico Martínez, c. 1603].

2. Haec svnt Acta Capituli Provincialis... Mexici: Apud Henricum Martinez, 1604.

3. In nomine domini nostri lesv Xpi et beatissimae virginis Mariae... Mexici: Apud Henricum Martinez, [Sin información de año, pero c. 1606].

4. In nomine domini nostri lesv Christi et beatissimi dominici patris nostri... México: Apud Henricum Martinez, Anno 1608.

5. Acta Capitvli Provincialis... Mexici: Ex Officina Henrici Martinez, 1610.

6. Acta Capitvli Provincialis... México: Ex officina Didaci Gutierrez, 1632.

Por último, la relevancia de estos hallazgos conduce a otro tipo de generación del conocimiento: el trasvase de los resultados de la aplicación de la corriente teórico-metodológica de la tipobiblioiconografía nos lleva a la identificación de nuevos matices del complejo mundo editorial mexicano. El hecho de la recurrencia de falta de preliminares preceptivos en las actas capitulares de la Orden de Predicadores aquí presentadas, que recorre todo el siglo XVII, permite formular conclusiones acerca de este interesante fenómeno editorial, tomando como base la tipología textual de los impresos y aunque no se haya localizado hasta ahora en documentación del periodo ninguna excepción legal al respecto. El recorrido llevado a cabo evidencia un nuevo fenómeno editorial, 
cuyo estudio se inaugura con este trabajo: el afianzamiento de la elaboración de ediciones de corte "privado" o "particular" en la imprenta mexicana del siglo XVII.

Si bien durante el siglo XVI esto ocurrió de manera esporádica, especialmente entre el periodo que va desde la instauración de la imprenta (1540) hasta la implementación de las directrices del Primer Concilio Mexicano (1555) -que reguló la impresión de libros en el ámbito local- y de la Pragmática de 1558, en el siglo XVII el fenómeno se consolida de tal manera que circulan recurrentemente obras impresas carentes de los preliminares administrativo-legales preceptivos (aprobaciones, censuras, licencias, cotejos, etc.), sin ninguna restricción o seguimiento por parte de las autoridades reguladoras del libro, debido

a que se trataba de ediciones de circulación privada dentro del ámbito de una orden religiosa y por tener finalidad normativa.

\section{Referencias}

Andrade, Vicente de P. Ensayo bibliográfico mexicano del siglo XVII. México: Imprenta del Museo Nacional, 1899.

Beristáin de Souza, José Mariano. Biblioteca Hispanoamericana Septentrional. 3 vols. México: Universidad Nacional Autónoma de México, 1980-1981.

Bouza, Fernando. "Reinos, imprentas y mercados en tiempos de Felipe IV. El libro en la monarquía y una monarquía en libros". Conferencia magistral. II Foro Editorial de Estudios Hispánicos y Americanistas, Cádiz, abril de 2011.

Eguiara y Eguren, Juan José. Bibliotheca mexicana. Coordinación de Ernesto de la Torre Villar. México: Universidad Nacional Autónoma de México, 1986.

Fernández Valladares, Mercedes. "De la tipobibliografía a la biblioiconografía. Consideraciones metodológicas para un Repertorio digital de materiales iconográficos de los impresos españoles del siglo XVI". En La palabra escrita e impresa: libros, bibliotecas, coleccionistas y lectores en el mundo hispano y novohispano: in memoriam Víctor Infantes \& Giuseppe Mazzocchi. Edición de Juan-Carlos Conde y Clive Griffin. Spanish Series 172, 57-98. Nueva York; Oxford: s. e., 2020.

Fernández Valladares, Mercedes. La imprenta en Burgos (1501-1560). Madrid: Arco Libros, 2005.

Gallardo, Bartolomé José. Biblioteca española de libros raros y curiosos. 4 vols. Madrid: Imprenta y Estereotipia de M. Rivadeneyra, 1863-1889.

León Pinelo, Antonio de. Epítome de la Bibliotheca Oriental y Occidental, náutica y geográfica. Añadido y enmendado nuevamente... por el Marqués de Torre Nueva. 2 vols. Madrid: Francisco Martínez Abad, 1737-1738. 
Maza, Francisco de la. Enrico Martínez: cosmógrafo e impresor de Nueva España. México: Universidad Nacional Autónoma de México, Instituto de Investigaciones Bibliográficas, 1991.

Medina, José Toribio. La imprenta en México (1539-1821). Vols. 1-2. Santiago de Chile: Imprenta del autor, 1907-1908.

Moll, Jaime. "La justificación de las matrices y el estudio de las letrerías". En De la imprenta al lector. Estudios sobre el libro español de los siglos XVI al XVIII, 109-118. Madrid: Arco Libros, 1994.

Norton, Frederick John. "Typographical Evidence as an Aid to the Identification and Dating of Unsigned Spanish Books of the Sixtheenth Century". Iberoromania, núm. 2 (1970): 96-103.

Pedraza Gracia, Manuel José. "Illustrating and Publishing on the Hand-Press in Spain from Fifteenth to the Eighteenth Century: The Ownership of Icono-Typographic Resources". En Illustration and Ornamentation in the Iberian Book World, 1450-1800. Edición de Alexander S. Wilkinson, 61-86. Leiden: Brill, 2022.

Puttick \& Simpson. Catalogue of an Extraordinary Collection of Books and Mss. Almost Wholly Relating to the History and Literature of North and South America. Londres: Puttick \& Simpson, 1869.

Ramírez, José Fernando. Obras, opúsculos históricos. 3 vols. México: Imp. de V. Agüeros, 1898.

Rodríguez Domínguez, Guadalupe. Biblioiconografía mexicana de los siglos XVI y XVII. Repositorio institucional de la Universidad Autónoma de San Luis Potosí. México, 2020. www.biblioiconografiamexicana.buap.mx.

Rodríguez Domínguez, Guadalupe. La imprenta en México en el siglo XVI. Mérida: Editora Regional de Extremadura, 2018.

Salvá y Mallén, Pedro. Catálogo de la Biblioteca de Salvá. Valencia: Imprenta de Ferrer de Orga, 1963.

Vervliet, Hendrik D. L. Sixteenth-Century Printing Types of the Low Countries. Prefacio de Harry Carter. Ámsterdam: Menno Hertzberger \& Co., 1968. 